\title{
Putting Faces to Names: Snapshots of Two Committee Meetings, 95 Years Apart, Emphasize Continuous International Cooperation in the Atmospheric Sciences
}

\author{
Hans VOLKERT* \\ Deutsches Zentrum für Luft- und Raumfahrt, Institut für Physik der Atmosphäre, 82234 Oberpfaffenhofen, Germany
}

(Received 23 December 2016; accepted 17 January 2017)

\begin{abstract}
Citation: Volkert, H., 2017: Putting faces to names: Snapshots of two committee meetings, 95 years apart, emphasize continuous international cooperation in the atmospheric sciences. Adv. Atmos. Sci., 34(5), 571-575, doi: 10.1007/s00376-0176329-6.
\end{abstract}

\section{Introduction}

Spectacular advances have been made in the atmospheric sciences on a global level during a period of one hundred years or more, which is arguably most evident through "the quiet revolution of numerical weather prediction" (Bauer et al., 2015). A cornerstone of such scientific success is generally regarded to be steady and orchestrated international cooperation. The intergovernmental World Meteorological Organization (WMO) has since 1952 been serving as the global umbrella organization for the National Hydro-Meteorological Services, with its work divided into a number of technical commissions. However, nongovernmental activities date back much further, e.g., to the first International Meteorological Congress in 1873, in Vienna, Austria, and the International Meteorological Conference in 1891, in Munich, Germany. The latter brought together some 35 directors of meteorological services in their personal capacities, rather than as governmental delegates. It was then decided to structure the work through technical sub-committees (Davies, 1990, p. 4 ), one of which was tasked with, and named, the Measurement of the Motion and Altitude of Clouds. Years later, it was renamed as the International Commission for the Scientific Investigation of the Upper Air, and can be regarded as a forerunner of today's Commission for Atmospheric Sciences (CAS) of the WMO. Nowadays, the WMO possesses a rich sub-structure, which partly reaches beyond its bounds in the form of the World Climate Research Programme (WCRP), with the International Council for Science (ICSU) and the International Oceanographic Commission (IOC) within UNESO as co-sponsors. The WCRP is composed of four core projects, one of which has been dealing with Stratospheretroposphere Processes and their Role in Climate (SPARC) since 1992, as documented in a unique series of as yet 48 newsletters, regularly appearing twice a year (available online

\footnotetext{
* Corresponding author: Hans VOLKERT

Email: Hans.Volkert@dlr.de
}

at http://www.sparc-climate.org/publications/newsletter/ ).

After the end of World War I, international cooperation formally started in the context of geophysics in a wider sense through the foundation of the International Union of Geodesy and Geophysics (IUGG) in 1919, with meteorology as one of its six sections (Good, 2000). Nowadays, this section exists as one of eight semi-autonomous associations within the IUGG, under the name of the International Association of Meteorology and Atmospheric Sciences (IAMAS), which has, since 2015, been having this journal (Advances in Atmospheric Sciences) as one of its formal information outlets, coordinated by the Chinese national committee of the IAMAS. As a recent example we mention the compact report about the International Radiation Symposium 2016 (Edkins et al., 2016) including photographs of all the participants as well as of prizewinners.

Behind the various organizational structures mentioned above lies the plain fact that (i) science is not an entirely abstract enterprise, but rather made by people for people, and (ii) the global extent of the earthly atmosphere requires international cooperation on a global scale. Group photographs from international gatherings can be regarded as visual datasets, the value of which is much enhanced, if the full names and geographical context (e.g., country of work) of every person are known. Ohring et al. (2009, Fig. 1 and Appendix) provided a most illustrative example through the illustrious joint grouping of the IAMAS commissions on Ozone (IOC) and on Radiation (IRC), when 128 persons (including some spouses and even children) met for a joint symposium in Oxford, UK, in the summer of 1959, invited by the atmospheric ozone research pioneer Gordon DOBSON. The subtle innovation of labeling all persons with small numbers arranged in columns and placing the explanations directly below the picture was also applied to the old-fashioned, though impressive, group photograph of the 38 participants at the International Meteorological Congress, which took place in Rome, Italy, in April 1879 (Volkert, 2008, Fig. 1). Furthermore, annotated group photographs are part of the historical compilations regarding the cooperative tasks tackled by 


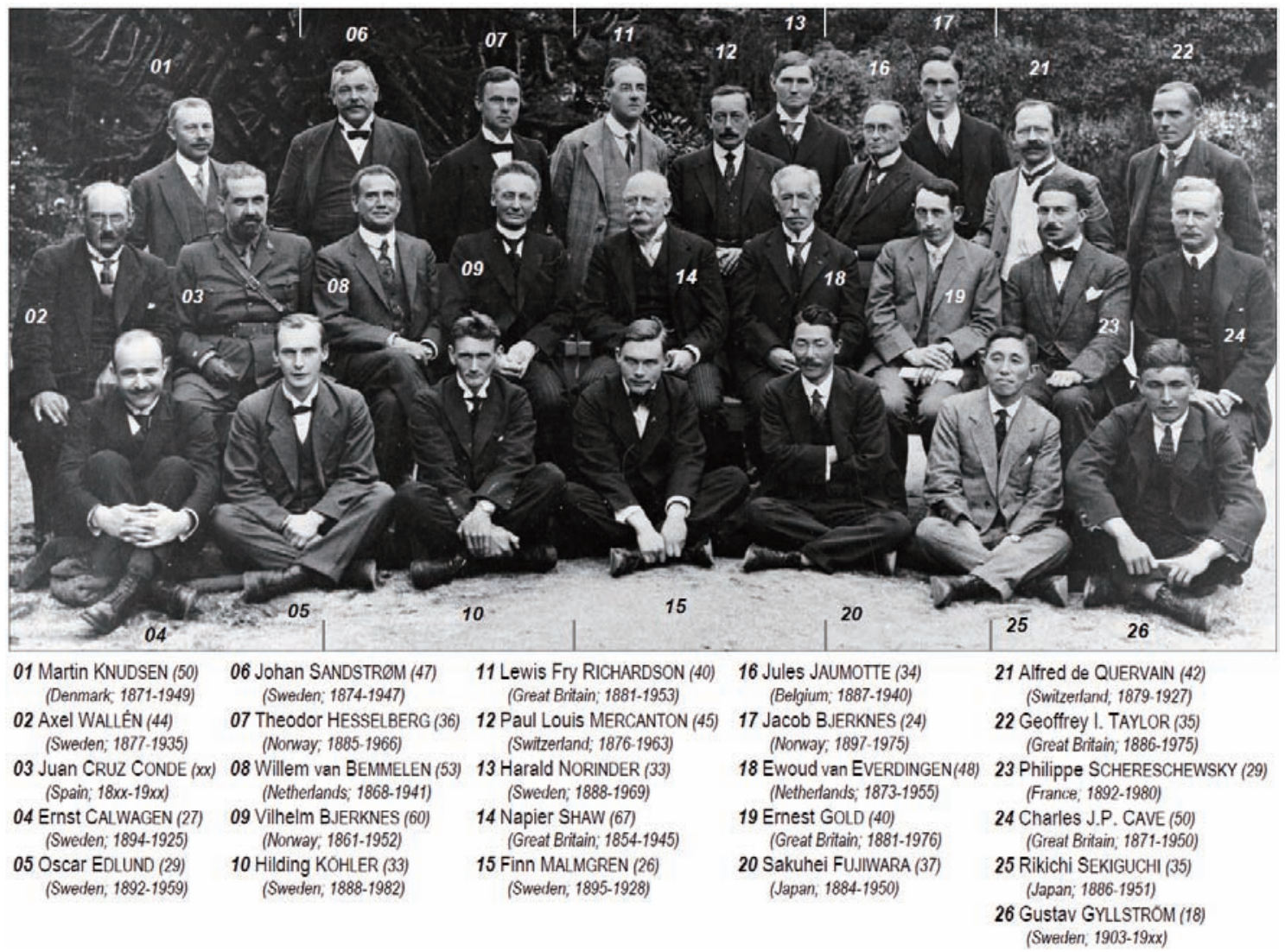

Fig. 1. Participants at the 8th meeting of the International Commission for the Scientific Investigation of the Upper Air, on 25 July 1921, in Bergen, Norway. The identification numbers run in six columns from back to front, each followed by the person's given name and SURNAME, age at the time of the meeting in brackets, country of work (not necessarily nationality), and life span. Photo credit: University Library Bergen.

the IAMAS/IRC (Bolle et al., 2008) and by the IAMAS/IOC (Bojkov, 2012). Examples include the IRC Symposium, 1972, in Sendai, Japan (Bolle et al., 2008; pp. 46, 47), the IRC Business Meeting, 1976, in Garmisch, Germany (Bolle et al., 2008; p. 45), the IRC Business Meeting, 2007, in Perugia, Italy (Bolle et al., 2008, p. 109), the Ozone Conference, 1936, in Oxford, UK (Bojkov, 2012; Fig. 4), the Joint Ozone and Radiation Symposium, 1959, in Oxford, UK (Bojkov, 2012; Fig. 10), and the Ozone Symposium, 1972, in Arosa, Switzerland (Bojkov, 2012; Fig. 13).

The aim of this article is to add two more annotated group photographs of active working groups to this distributed collection - one related to an event that proved to be highly conducive to progress in atmospheric science research nearly a century ago (the Bergen meeting of 1921), and another that continued to coordinate voluntary research in the present day (the Berlin meeting of 2016). The following two sections deal in turn with these meetings, with further remarks being made in the final section. The article's title deliberately inverts the common expression "putting names to faces" as, in science, the names of persons are often better known then their appearance, in contrast to ordinary life where we tend to see people first and then get to hear and memorize their names at a later point in time.

\section{Meeting in Bergen, July 1921}

The 8th meeting of the International Commission for the Scientific Investigation of the Upper Air was held in Bergen, Norway, from Monday to Friday, 25-29 July 1921. As Ernest GOLD, a participant from the UK, vividly explained, a new routine was established:

"The preceding (7th) meeting of this Commission was held in Vienna in 1912, when, it may be recalled, Professor Bjerknes secured the adoption of a resolution for expressing pressure in millibars so far as information about the upper air was concerned. At that meeting the time was mainly occupied with business questions, and such scientific discussion as there was merely filled up the brief intervals which could be spared from the business meetings.

At the meeting at Bergen a new principle was adopted. The leading place was given to scientific contributions from the members of the Commission and other meteorologists interested in the work, on the ground that plans for international work could only be well devised if the members first got clear ideas about the objects to be aimed at in the investigations and about the methods of applying the observations to the solution of definite meteorological problems. This new procedure has advantages, but it is doubtful if it could be applied suc- 


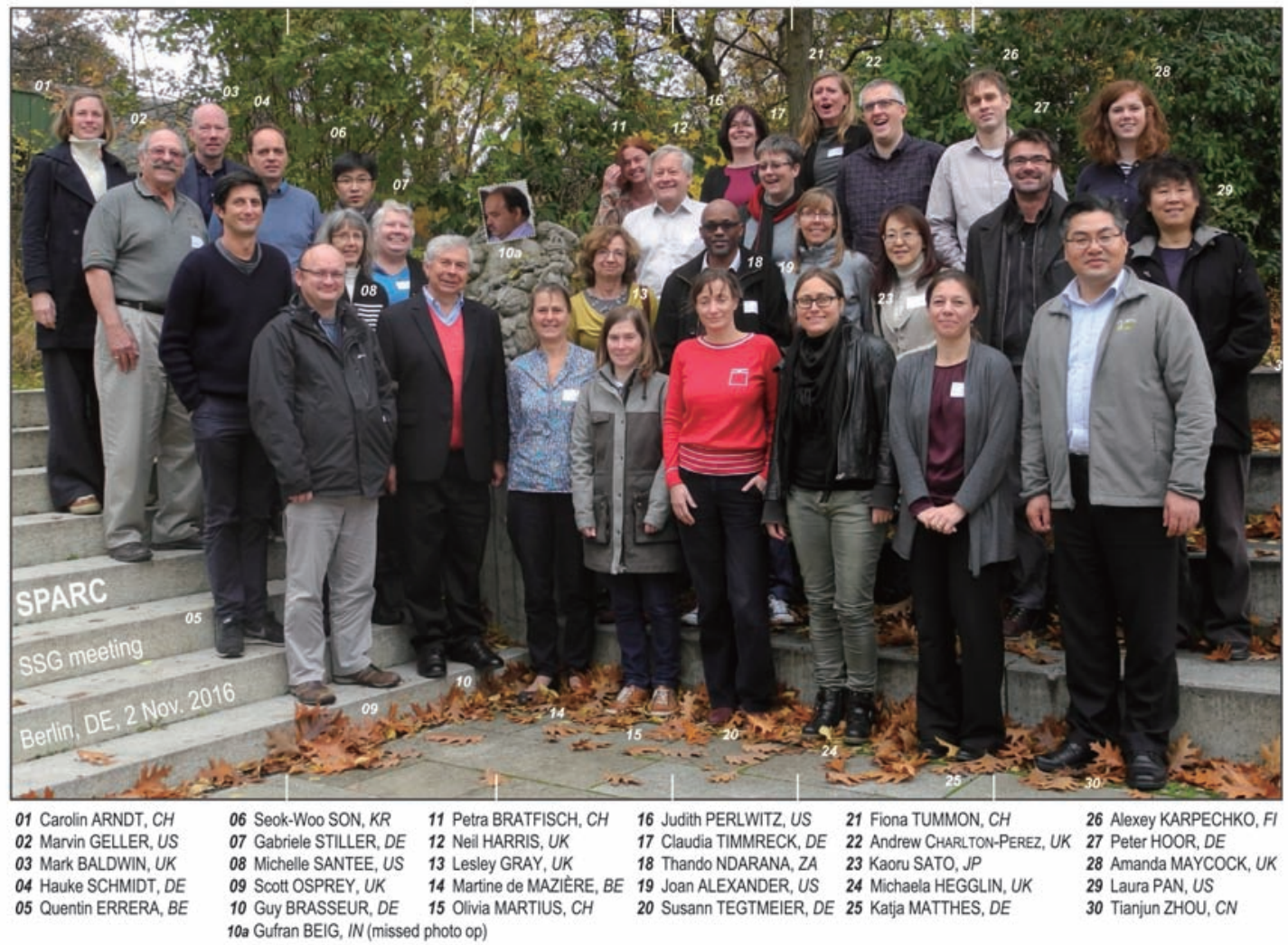

Fig. 2. Participants of the 24th SPARC Scientific Steering Group meeting, on 2 November 2016, in Berlin, Germany. Identification numbers run in six columns from back to front, each followed by the person's given name, SURNAME, and country code of work (not necessarily nationality). The group, having come from four continents, assembled before lunch around a stone putto in the park of Harnack-Haus. Country codes: BE, Belgium; CH, Switzerland; CN, China; DE, Germany; FI, Finland; IN, India; JP, Japan; KR, Korea; UK, United Kingdom; US, United States; ZA, South Africa. Photo credit: Hans VOLKERT.

cessfully except under the inspiration of a Bjerknes.

On Monday, July 25th, the delegates to the meeting were received by the President, Prof. V. BJERKNES, at the Geophysical Institute, and after an individual tea and collective photograph, they listened to an account by Mr. BJERKNES, junior, of further developments in the study of the Polar Front." (Gold, 1921, p. 215).

The result of the collective photograph after tea is presented here as Fig. 1. The host, Vilhelm BJERKNES (\#09) is sitting in the center, next to the senior of the group, Sir Napier SHAW (\#14), former director of the UK Meteorological Office and, at the time, a professor at Imperial College, London. Other participants whose names are still familiar include Axel WALLÉN (\#02), Theodor HESSELBERG (\#07), Lewis Fry RICHARDSON (\#11), Jacob BJERKNES (\#17), Ernest GOLD (\#19), and Geoffrey I. TAYLOR (\#22). We refrain from mentioning more details about the participants and their contribution to the atmospheric sciences, as a very personal account was published 56 years after the event by the participant Philippe SCHERESCHEWSKY (\#23; 1977), where he quoted from a letter by Sverre PETTERSEN: "Rarely have I seen a photograph so laden with talent".

Notwithstanding the individual personalities, note the very effective placement of the 26 persons in three slightly curved rows, with seven mostly junior colleagues sitting cross-legged on the ground, in front of nine more senior persons seated on garden benches. The remaining 10 participants stand behind in a rather leisurely manner. All persons are dressed in a formal elegance, which was customary for academics at that time, but also express traces of individual taste. The host's dedication to make a lasting impression to both the invited guests and to later viewers can be clearly sensed. The distribution of the ages of the participants varies from 18 to 67 years, highlighting the fact that three generations of researchers cooperated, including some younger assistants of BJERKNES senior, established scientists from abroad, and a number of prominent seniors. Barely three years after the end of World War I, the geographical distribution of participants leaned towards Scandinavia, allied and politically neutral states, with the German speaking grouping not represented.

The close and lasting link to the commission's parent body, the International Meteorological Committee (IMC), is evident through the combined presence of Napier SHAW (\#14; IMC President, 1919-23), Ewoud van EVERDINGEN (\#18; IMC President, 1923-35) and Theodor HESSELBERG 
(\#07; IMC President, 1935-46).

We turn next to the present day and look for traces of the personal spirit injected by Vilhelm BJERKNES into formal arrangements of meteorological cooperation that are still in existence.

\section{Meeting in Berlin, November 2016}

As a core project of the WCRP, the SPARC initiative started informally in 1992, amidst a 12-day scientific meeting under the title The Role of the Stratosphere in Global Change (Chanin and Geller, 1993). Since then, the annual business meetings of the SPARC Scientific Steering Group (SSG) have mostly been accompanied by scientific workshops. The SPARC-SSG meeting in 2016 was preceded by a noon-to-noon workshop on 31 October and 1 November, entitled "Challenges for Climate Science - Synergies between SPARC and the WCRP Grand Challenges". Thus, the then novel (and also natural) idea of 1921 prevails to combine scientific discussions with administrative decisions.

The scientific workshop and the SSG meeting both took place at Harnack-Haus in Berlin, Germany. This purposebuilt establishment for scientific interchange, informal discussion, as well as larger, more formal events, was opened in 1929 and has had numerous Nobel prize winners in science as its guests. Used by American military personnel after World War II, it was reopened as a conference center of the Max Planck Society in 2000 (www.harnackhausberlin.mpg.de/4318436/history).

On 2 November 2016, members of the SPARC SSG, representatives of the various SPARC activities, and staff of the SPARC office at ETH-Zurich, Switzerland, assembled at the beginning of the lunch break for their photo opportunity in the park of Harnack-Haus (Fig. 2). In total, 30 persons naturally grouped themselves on the staircase around a stone putto and smiled to an amateur photographer. A colleague from India missed the occasion; a portrait of his head was inserted later at the location of the putto's head.

Among the senior participants were Marvin GELLER (\#02; SSG Co-chair, 1992-2002), Guy BRASSEUR (\#10; Chair of the WCRP Joint Scientific Committee), Neil HARRIS (\#12; SSG Co-chair), Judith PERLWITZ (\#17, SSG Cochair), and Joan ALEXANDER (\#19, SSG Co-chair 201315). In comparison with Fig. 1, the appearance of the participants is definitely less formal, and there are more women (17) present than men (14). The delegates were working in 11 countries across four continents, confirming that achieving proper balance in terms of gender and geographical distribution is being tackled successfully. Apparent in both group photographs is an atmosphere of good humor and openness among colleagues.

On a closing note, readers may be interested to learn that quite a number of group photographs (including names of the persons present) from the annual SSG meetings are included in the regularly appearing SPARC newsletters, as mentioned in the introduction.

\section{Further remarks}

Annotated group photographs are nothing new. Still, it is felt that adding more information than just names, e.g., full given names, country of work, and life spans of persons in older samples, would considerably enhance the value of the informational content for the benefit of readers, in particular those from funding agencies or even historians of science. A growing awareness of the decisive importance of international cooperation on a voluntary basis for progress in a discipline as global in nature as the atmospheric sciences is regarded as a prerequisite for both the discipline's self-esteem and further progress. Admittedly, the chosen samples of 1921 and 2016 may appear selected quite arbitrarily. Nevertheless, they nicely illustrate that voluntary international committee work has a long tradition in meteorology.

More published examples are available, either in formal publications [e.g., the gathering of 140 persons at the IUGG/IAMAS/ICDM International Workshop in Kunming, China, in August 2012 ( $\mathrm{Li}$ et al., 2016)], or on websites [e.g., the follow-up International ICDM/ICPM Workshop in Bergen, Norway, in March 2015, with 72 participants (www. iamas.org/meetings-data/HLD2015-Groupphoto.pdf). Also of relevance is the documentation from regular project meetings on a national scale, especially when they are enhanced by senior visitors from abroad. The collaborative research center "Waves to Weather" (www.w2w.meteo.physik.unimuenchen.de/meetings), in Germany, is a good example in the latter category, not least through its direct links to the HIWeather project of the WMO's World Weather Research Programme (WWRP).

In conclusion, this article highlights the science-historical relevance of what has grown to be a broad collection of annotated group photographs of scientific meetings, at a time when scientific unions and their related international associations are heading towards the centenary of their inauguration (Ismail-Zadeh, 2016).

Acknowledgements. Marianne PAASCHE, University of Bergen Library, kindly made available a high-resolution scan of the 1921 group photograph (as the core information for Fig. 1). The suggestion by Tianjun ZHOU to adapt a poster presented at the SPARC 2016 Workshop for the "New \& Views" section of Advances in Atmospheric Sciences was appreciated, as well as the editorial assistance provided by Zheng LIN and Ling ZHOU. Support for this study was provided by the "Waves to Weather" initiative (SFB/TRR 165) of the German Research Foundation (DFG).

\section{REFERENCES}

Bauer, P., A. Thorpe, and G. Brunet, 2015: The quiet revolution of numerical weather prediction. Nature, 525, 47-55, doi: 10.1038 /nature 14956.

Bojkov, R. D., 2012: International Ozone Commission: History and Activities. IAMAS Publication Series No. 2, IAMAS, iv $+100 \mathrm{pp}$. [Available online at http://www.iamas.org/Pdfs/ IAMAS-PubSer-No2.pdf] 
Bolle, H. J., F. Möller, and J. London, 2008: International Radiation Commissions 1896 to 2008: Research into Atmospheric Radiation from IMO to IAMAS. IAMAS Publication Series No. 1, IAMAS, iv + $141 \mathrm{pp}$. [Available online at http://www.iamas.org/Pdfs/IAMAS-PubSer-No1.pdf]

Chanin, M. L., and M. Geller, 1993: Greetings from SPARC. SPARC newsletter no. 1, 2. [Available online at http:// www.sparc-climate.org/fileadmin/customer/6_Publications/ Newsletter_PDF/1_SPARCnewsletter_Jul1993_redFile.pdf]

Davies, S. A., 1990: Forty Years of Progress and Achievement. A Historical Review of WMO. WMO-No. 721, Secretariat of the World Meteorological Organization, viii +205 pp. [Available online at http://library.wmo.int/pmb_ged/wmo_721_en.pdf]

Edkins, N., W. Schmutz, L. Egli, R. Davies, T. Aoki, and G. McFarquhar, 2016: The International Radiation Symposium 2016. Adv. Atmos. Sci., 33, 1325-1328, doi: 10.1007/s00376016-6180-1.

Gold, E., 1921: Meeting of the international commission for the scientific investigation of the upper air at Bergen. Meteorol. Mag., 56, 215-217. [Available online at https://digital. nmla.metoffice.gov.uk/file/sdb\%3AdigitalFile\%7C02b18335f225-4fed-8731-cb8cfede75ba/]

Good, G. A., 2000: The assembly of geophysics: Scientific disciplines as frameworks of consensus. Studies in History and Philosophy of Science Part B: Studies in History and Philosophy of Modern Physics, 31, 259-292, doi: 10.1016/S13552198(00)00018-6.
Ismail-Zadeh, A., 2016: Geoscience international: The role of scientific unions. History of Geo- and Space Sciences, 7, 103123, doi: 10.5194/hgss-7-103-2016.

Li, J. P., R. Swinbank, R. Grotjahn, and H. Volkert, Eds., 2016: Dynamics and Predictability of Large-Scale, High-Impact Weather and Climate Events. Special Publications of the International Union of Geodesy and Geophysics Series, Vol. 2. Cambridge University Press.

Ohring, G., R. D. Bojkov, H.-J. Bolle, R. D. Hudson, and H. Volkert, 2009: Radiation and Ozone: Catalysts for advancing international atmospheric science programs for over half a century. Bull. Amer. Meteor. Soc., 90, 1669-1681, doi: 10.1175/ 2009BAMS2766.1.

Schereschewsky, P. L., 1977: Afterword — Remarks presented after the Bjerknes memorial lecture. Bull. Amer. Meteor. Soc., 58, 400-401.

Volkert, H., 2008: Die deutsche Meteorologie als Motor und Nutznießer von internationaler Zusammenarbeit: Wichtige Institutionen und Persönlichkeiten von 1875 bis 2005. (in German; translated title: German meteorology as motor for and beneficiary of International Cooperation: Important Institutions and Personalities during the Period 1875 to 2005). In: G. Tetzlaff, C. Lüdecke and H. D. Behr Eds., 125 Jahre Deutsche Meteorologische Gesellschaft (125 years of German Meteorological Society), Annalen der Meteorologie, 43, 17-24. [Available online at http://elib.dlr.de/55963/1/ Vorabdruck-125aDMG-Volkert-IntZusArbeit.pdf] 